\title{
Correlation of amniotic fluid index with fetomaternal outcome
}

\author{
Vidyasagara M. ${ }^{1}$, Chandrashekhar T. ${ }^{2}$, Sunil S. Raikar ${ }^{1 *}$ \\ ${ }^{1}$ Department of Obstetrics and Gynecology, Gadag Institute of Medical Sciences, Gadag, Karnataka, India \\ ${ }^{2}$ Department of Obstetrics and Gynecology, Vijayanagara Institute of Medical Sciences, Ballari, Karnataka, India
}

Received: 14 June 2021

Revised: 08 July 2021

Accepted: 09 July 2021

*Correspondence:

Dr. Sunil S. Raikar,

E-mail: raikarjodhpurin@gmail.com

Copyright: (c) the author(s), publisher and licensee Medip Academy. This is an open-access article distributed under the terms of the Creative Commons Attribution Non-Commercial License, which permits unrestricted non-commercial use, distribution, and reproduction in any medium, provided the original work is properly cited.

\section{ABSTRACT}

Background: Amniotic fluid acts like a protective cover around the baby. Advances in ultrasound have increased early detection of abnormal amniotic fluid volumes. Any variation in the amniotic fluid volume warrants antenatal foetal surveillance.

Methods: 300 pregnant women between 37 to 40 weeks of gestation were included in the study. A detailed history, examination and ultrasound was done. Pregnant women were divided into 3 groups' i.e. normal liquor, oligohydramios and polyhydramnios. All the women were closely monitored during labour and puerperium. Follow-up was done till 7 days post-delivery. Maternal and neonatal data were collected.

Results: 300 pregnant women were included in the study, out of which 221 had normal amniotic fluid index (AFI), 64 had oligohydramnios and 15 had polyhydramnios. All baseline characteristics were comparable between the groups except body mass index (BMI). Incidence of meconium stained liquor was significantly higher in oligohydramnios compared to normal AFI and polyhydramnios groups (34.4\% versus $10.5 \%$ versus $13.3 \% ; \mathrm{p}=0.0001)$. Caesarean section rates were significantly higher in polyhydramnios and oligohydramnios compared to normal AFI group (73.3\% versus $70.3 \%$ versus $19.9 \%$; $\mathrm{p}=0.0001$ ). Higher cases of low birth weight were recorded in oligohydramnios group compared to normal AFI and polyhydramnios group group (32.8\% versus $18.6 \%$ versus $13.3 \%$; $=0.011)$. Neonatal intensive care unit (NICU) admissions were higher in oligohydramnios (35.9\%) and polyhydramnios (33.3\%) compared to normal AFI group (35.9\% versus $33.3 \%$ versus $12.7 \%$; $\mathrm{p}=0.0001)$.

Conclusions: Abnormal liquor volumes are associated with increased caesarean section rates, NICU admissions and neonatal mortality. Careful assessment of pregnant women is imperative for proper counselling and management.

Keywords: Oligohydramnios, Polyhydramnios, Caesarean section, NICU admission, AFI

\section{INTRODUCTION}

Amniotic fluid provides protection and mobility to the growing foetus. It is sustained by a dynamic balance between the foetal urine production, foetal swallowing and intra-membranous absorption. Adequate amniotic fluid is required for normal foetal lung maturation and musculoskeletal growth. ${ }^{1}$ Any variation in the amniotic fluid volume indicates difficulty in the foetal maturation or comorbidities in the mother. ${ }^{2}$
With the advent of ultrasound, amniotic fluid volume assessment has become an integral part of antenatal examination. Amniotic fluid volume is assessed by ultrasound in terms of amniotic fluid index (AFI). ${ }^{3}$ Any changes in the AFI can cause harm to the growing fetus., ${ }^{2,3}$ Decreased amniotic fluid is termed as oligohydramnios is associated with conditions like uteroplacental insufficiency, pregnancy induced hypertension, diabetes, congenital anomalies and foetal growth restriction. ${ }^{4}$ Similarly, polyhydramnios means increased amniotic fluid is associated with maternal diabetes, congenital anomalies 
and foetal hydrops. ${ }^{3,5}$ Both, oligohydramnios and polyhydramnios is thought to be associated with labour complications, resulting in increased perinatal mortality and morbidity. ${ }^{6}$

Therefore, the present study was conducted to find out the feto-maternal outcome associated with amniotic liquor volume in a tertiary hospital in Karnataka, India.

\section{METHODS}

This is prospective observational study conducted at Department of Obstetrics and Gynaecology, Vijayanagara Institute of Medical Sciences, Ballari from January 2018 to December 2018. Institutional ethical clearance was obtained (VIMS/STD/PG/IEC/18/2018-19).

All pregnant women approaching the labour room screened for eligibility. Single live intrauterine gestations between 37-40 weeks with intact membranes were included in the study. Previous uterine scar and congenital anomalies were excluded. Eligible cases were explained regarding the study and written consent taken. A total of 300 cases were included in the study. Non-stress test was done at admission. Detailed history was taken and ultrasound examination was done to assess the AFI. AFI was measured using Phelan's four quadrant ultrasound technique. The uterus was arbitrarily divided into four quadrants by the umbilicus transversely and the lineanigra vertically. The largest vertical pocket free of foetal parts and umbilical cord loops in each quadrant was measured and sum of these measurements was calculated. Pregnant women were divided into 3 groups based on AFI i.e. oligohydramnios $(\mathrm{AFI}<5)$, polyhydramnios $(\mathrm{AFI}>25)$ and normal AFI (AFI=5-25). Close monitoring during labour and puerperium was done. Follow up was done till 7 days post-delivery. Maternal data and neonatal data were collected.

Collected data were entered into statistical package for the social sciences (SPSS) version 25 (IBM Corp., USA). For qualitative variables, data were expressed as number or percentages. Comparison of qualitative variables was done using Chi-square test and Fisher's exact test. Student t test was used to compare the quantitative data in the study.

\section{RESULTS}

We studied 300 pregnant women, out of which 221 had normal AFI, 64 had oligohydramnios and 15 had polyhydramnios (Table 1). Mean maternal age was $22.51 \pm 3.17,22.69 \pm 3.12$ and $24.47 \pm 3.76$ in normal AFI, oligohydramnios and polyhydramnios groups respectively. Mean BMI was significantly higher in polyhydramnios group $(25.52 \pm 3.55)$ compared to normal AFI (23.85 \pm 2.66$)$, oligohydramnios (23.31 \pm 2.41$)$. Incidence of primigravida was $59.7 \%, 71.9 \%$ and $46.7 \%$ in normal AFI, oligohydramnios and polyhydramnios groups respectively. Preclampsia was the most common comorbidity in normal AFI group (11.8\%) and oligohydramnios group (21.9\%). Gestational diabetes mellitus was the most common co-morbid condition in polyhydramnios group $(26.7 \%)$.

Large number of pregnant women from normal AFI group underwent oxytocin induction compared to other groups (Table 2). Incidence of meconium stained liquor was significantly higher in oligohydramnios compared to normal AFI and polyhydramnios groups $(34.4 \%$ versus $10.5 \%$ versus $13.3 \%$; $\mathrm{p}=0.0001)$. Caesarean section rates were significantly higher in Polyhydramnios and Oligohydramnios compared to normal AFI group $(73.3 \%$ versus $70.3 \%$ versus $19.9 \%$; $\mathrm{p}=0.0001$ ).

Mean Neonatal body weight was statistically higher in polyhydramnios group compared to normal AFI group and oligohydramnios group $(3.03 \pm 0.55$ versus $2.76 \pm 0.39$ versus $2.54 \pm 0.47 ; \mathrm{p}=0.049$ ) (Table 3 ). Higher cases of Low birth weight were recorded in oligohydramnios group compared to normal AFI and polyhydramnios group group ( $32.8 \%$ versus $18.6 \%$ versus $13.3 \%$; $\mathrm{p}=0.011$ ). Comparing the APGAR scores at 1 and 5 minutes, higher number of neonates had low scores in polyhydramnios group compared to other groups. NICU admissions were higher in oligohydramnios (35.9\%) and polyhydramnios $(33.3 \%)$ compared to normal AFI group (35.9\% versus $33.3 \%$ versus $12.7 \%$; $\mathrm{p}=0.0001)$. Respiratory distress was the most common cause for NICU admission in all the groups. Early neonatal mortality rate was significantly higher in oligohydramnios and polyhydramnios groups compared to normal AFI group $(0.5 \%, 6.25 \%$ and $6.7 \%$; $=0.006)$.

Table 1: Baseline characteristics among different groups.

\begin{tabular}{|lllll|}
\hline Characteristics & Normal $(\mathbf{n = 2 2 1})$ & Oligo-hydramnios $(\mathbf{n = 6 4 )}$ & Poly-hydramnios $(\mathbf{n = 1 5})$ & P value \\
\hline Maternal age & $22.51 \pm 3.17$ & $22.69 \pm 3.12$ & $24.47 \pm 3.76$ & $0.073^{*}$ \\
\hline Gestational age & $38.93 \pm 0.96$ & $38.96 \pm 1.18$ & $38.39 \pm 1.14$ & $0.127^{*}$ \\
\hline BMI & $23.85 \pm 2.66$ & $23.31 \pm 2.41$ & $25.52 \pm 3.55$ & $0.015^{*}$ \\
\hline Hemoglobin $(\mathbf{g m} / \mathbf{d l})$ & $10.4 \pm 1.4$ & $10.6 \pm 1.2$ & $10.8 \pm 1.2$ & $0.541^{*}$ \\
\hline$<7$ & $4(1.8)$ & 0 & 0 & $0.450^{\#}$ \\
\hline $7-10$ & $88(39.8)$ & $22(34.4)$ & $4(26.6)$ & $6(40)$ \\
\hline $10-11$ & $45(20.3)$ & $22(34.4)$ & & \\
\hline$>11$ & $84(38)$ & $20(31.2)$ & & \\
\hline Booked status & & $63(98.4)$ & & $0.494^{\#}$ \\
\hline Booked & $214(96.8)$ & & & \\
\hline
\end{tabular}

Continued. 


\begin{tabular}{|lllll|}
\hline Characteristics & Normal $(\mathbf{n = 2 2 1})$ & Oligo-hydramnios $(\mathbf{n = 6 4})$ & Poly-hydramnios $(\mathbf{n = 1 5})$ & P value \\
\hline Unbooked & $7(3.2)$ & $1(1.6)$ & 0 & \\
\hline Gravida & & & $7(46.7)$ & $0.780^{\#}$ \\
\hline Primigravida & $132(59.7)$ & $46(71.9)$ & $8(53.3)$ & \\
\hline Multigravida & $89(40.3)$ & $18(28.1)$ & $2(13.3)$ \\
\hline Co-morbidities & & & $1(6.7)$ \\
\hline Pre-eclampsia & $26(11.7)$ & $14(21.8)$ & $4(26.6)$ \\
\hline Gestational HTN & $7(3.1)$ & $1(1.5)$ & 0 \\
\hline Gestational DM & 0 & 0 & 0 \\
\hline RH negative pregnancy & $11(4.9)$ & $3(4.5)$ & $1(6.7)$ \\
\hline HBsAg positive & $3(1.3)$ & $2(3)$ & 0 & \\
\hline Hypothyroidism & $1(0.45)$ & $1(1.5)$ & 0 & \\
\hline Severe anaemia & $4(1.8)$ & 0 & $1(1.5)$ & \\
\hline Asthma & 0 & &
\end{tabular}

Data presented in $\mathrm{n}(\%)$ and mean $\pm \mathrm{SD}, *$ ANOVA, \#Kruskal Wallis test

Table 2: Intrapartum data among the different groups.

\begin{tabular}{|lllll|}
\hline Intrapartum data & Normal & Oligo-hydramnios & Poly-hydramnios & P value \\
\hline Induction by Dinoprostone & $10(4.5)$ & $3(4.6)$ & $1(6.6)$ & $0.931 \#$ \\
\hline Oxytocin augmentation & $99(44.7)$ & $15(23.4)$ & $3(20)$ & $0.03 \#$ \\
\hline Liqour & & & $2(13.3)$ & $0.0001 \#$ \\
\hline Meconium stained & $23(10.5)$ & $22(34.4)$ & $13(86.7)$ & \\
\hline Clear liquor & $198(89.5)$ & $42(65.6)$ & & \\
\hline Mode of delivery & & & $4(73.3)$ & \\
\hline LSCS & $44(19.9)$ & $45(70.3)$ & & \\
\hline Vaginal & $177(80.1)$ & $19(29.7)$ & $2(18.2)$ & \\
\hline Indications for LSCS & & & $1(9.1)$ & \\
\hline Arrest of descent & $4(9.1)$ & $2(4.4)$ & $0.259 \#$ \\
\hline $\begin{array}{l}\text { Cephalo-pelvic } \\
\text { disproportion }\end{array}$ & $7(15.9)$ & $2(4.4)$ & $4(36.3)$ & \\
\hline Deep transverse arrest & 0 & $1(2.2)$ & $3(27.3)$ & \\
\hline Elective & $18(40.9)$ & $23(51.1)$ & $1(9.1)$ & \\
\hline Fetal distress & $13(29.5)$ & $16(35.5)$ & 0 & \\
\hline Non progression of labour & $1(2.3)$ & 0 & $1(2.2)$ & \\
\hline Second stage arrest & $1(2.3)$ & & & \\
\hline
\end{tabular}

Data presented in $\mathrm{n}(\%)$, \#Kruskal Wallis test

Table 3: Neonatal data among different groups.

\begin{tabular}{|c|c|c|c|c|}
\hline Neonatal data & Normal & Oligo-hydramnios & Poly-hydramnios & P value \\
\hline \multicolumn{5}{|l|}{ Body weight (kg) } \\
\hline Mean \pm SD & $2.76 \pm 0.39$ & $2.54 \pm 0.47$ & $3.03 \pm 0.55$ & $0.049 *$ \\
\hline Normal $(\geq 2.5)$ & $179(80.9)$ & $42(65.6)$ & $12(80)$ & \\
\hline LBW (1.5-2.4) & $42(19.1)$ & $21(32.8)$ & $2(13.3)$ & \\
\hline $\operatorname{VLBW}(<1.5)$ & 0 & $1(1.5)$ & 0 & $0.011 \#$ \\
\hline Macrosomia (>4) & 0 & 0 & $1(6.7)$ & \\
\hline \multicolumn{5}{|c|}{ APGAR score at $1 \mathrm{~min}$} \\
\hline Normal & $196(88.7)$ & $51(79.7)$ & $10(66.7)$ & \\
\hline Low & $25(11.3)$ & $13(20.3)$ & $5(33.3)$ & 0.019\# \\
\hline \multicolumn{5}{|c|}{ APGAR score at $5 \mathrm{~min}$} \\
\hline Normal & $208(94.1)$ & $55(85.9)$ & $11(73.3)$ & \\
\hline Low & $13(5.9)$ & $9(14.1)$ & $4(26.7)$ & $0.005 \#$ \\
\hline \multicolumn{5}{|l|}{ NICU admission } \\
\hline Total & $31(14.1)$ & $23(35.9)$ & $5(33.3)$ & $0.0001 \#$ \\
\hline Respiratory distress & $19(61.3)$ & $13(56.5)$ & $2(40)$ & \\
\hline
\end{tabular}

Continued. 


\begin{tabular}{|lllll|}
\hline Neonatal data & Normal & Oligo-hydramnios & Poly-hydramnios & P value \\
\hline Birth asphyxia & $8(25.8)$ & $6(26.1)$ & $2(40)$ & $0.346 \#$ \\
\hline Fetal hypoglycaemia & 0 & 0 & $1(10)$ \\
\hline Sepsis & $4(12.9)$ & $4(17.4)$ & 0 \\
\hline Neonatal mortality & & & & $0.006 \#$ \\
\hline Total & $1(0.45)$ & $4(6.25)$ & $1(6.7)$ & $0.458 \#$ \\
\hline Birth asphyxia & 0 & $1(25)$ & 0 \\
\hline $\begin{array}{l}\text { Meconium aspiration } \\
\text { syndrome }\end{array}$ & $1(100)$ & $1(25)$ & 0 \\
\hline Sepsis & 0 & $2(50)$ & & \\
\hline
\end{tabular}

Data presented in $\mathrm{n}(\%)$ and mean $\pm \mathrm{SD}, * \mathrm{ANOVA}$, \#Kruskal Wallis test

\section{DISCUSSION}

In our study, majority of the patients had normal AFI. Frequency of normal liquor volume, oligohydramnios and polyhydramnios were $73.7 \%, 21.3 \%$ and $15 \%$, respectively. All the baseline characteristics were comparable between the groups (Table 1) except BMI. BMI was higher in polyhydramnios group compared to other two groups. On a rational thought this difference is not important because diabetes mellitus is one of the cause of polyhydramnios. 4 cases $(26.6 \%)$ of gestational diabetes mellitus were present in polyhydramnios group, while the other groups had none.

Early detection of abnormal liquor helps in decreasing the perinatal risks. In our study, Majority of the patients were booked at the hospital. $98.4 \%$ of oligohydramnios, $96.8 \%$ of normal AFI and $100 \%$ of polyhydramnios were booked cases. Better awareness and availability of hospital services may be the reason for higher booked cases.

Lower segment caesarean section (LSCS) rates were high for both oligohydramnios $(70.3 \%)$ and polyhydramnios (73.3\%) groups. In both the groups, elective LSCS was the most common indication followed by foetal distress. Similar findings were found in other studies for oligohydramnios mothers. ${ }^{7-9}$ However, many studies had lower rates of caesarean section. ${ }^{10-12}$ Our study had a higher number of elective caesarean section, which may be the reason for this conflicting finding. Comparison between the indications of LSCS was not possible, because different studies had diverse set of indication. Overall LSCS rate in our study was $33.3 \%$.

Meconium liquor is recognized as potential for birth asphyxia. Only cases with thick meconium was documented, has it has association with perinatal outcome compared to thin meconium. In our study, $34.4 \%$ in oligohydramnios group had meconium stained liquor as compared to $10.4 \%$ in normal AFI group and $13.3 \%$ in the polyhydramnios group. In concordance to our study, Ravi et al $(27 \%)$ and Choudary et al (33\%) had similar observation of meconium stained liquor in oligohydramnios group. ${ }^{11,12}$

Abnormal liquor volume has been recognized as a clinical hallmark of impending severe perinatal compromise.
Various studies have shown relationship between increased perinatal morbidity and mortality in pregnancy with abnormal liquor volume. , $9,10,12^{2} 32.8 \%$ of neonates delivered to oligohydramnios mother were low birth weight. Similar finding was found in other studies as well. ${ }^{11,13}$ In a study by Tajinder et al, $10.3 \%$ of oligohydramnios mother delivered very low birth weight (VLBW) babies. ${ }^{13}$ This was higher compared to our study. This may be due to the exclusion of anomalous babies in our study.

Furthermore, higher numbers of neonates were admitted to NICU, who were delivered to mothers with oligohydramnios and polyhydramnios. NICU admissions were $35.9 \%$ and $33.3 \%$ in babies delivered to oligohydramnios and polyhydramnios mothers respectively. Similar findings were documented in other studies on oligohydramnios mothers. ${ }^{8,10,13}$ However, in a study conducted by Bhagat and Chawla documented higher rates $(92 \%)$ of NICU admission. ${ }^{14}$ In the same study, only $36 \%$ neonates were admitted in the NICU for more than 2 days. The drastic increase in the NICU admission may be due to the hospital protocols, which may vary from hospital to hospital.

Neonatal mortality in our study was $6.3 \%$ and $6.7 \%$ in oligohydramnios and polyhydramnios respectively. In concordance with our study, Chaudary et al documented similar findings neonatal death in cases with oligohydamnios. ${ }^{11}$ In a prospective study by Mathuriya et al neonatal mortality was significantly higher $(17.8 \%)$ in oligohydramnios mothers. ${ }^{10}$ Such a drastic increase in neonatal mortality may be due to large number of anomalous babies delivered to oligohydramnios mothers. $10 \%$ of oligohydramnios mothers delivered babies with anomalous babies.

We compared fetomaternal outcomes of all the three subgroups, i.e. oligohydramnios, polyhydramnios and normal AFI. But, it was an observational study and cases were recruited at term gestation in the labour room. Study contained a smaller number of polyhydramnios mothers which may have affected the results. There was no antenatal or postnatal follow-up. Long term complications were not studied as neonatal follow-up was done for 7 days. 
Despite some strong associations demonstrated with abnormal liquor volume, the prediction for at an individual level is generally poor. ${ }^{6}$ But, the association can be used as a prognostic factor for counselling and planning the management of the pregnant women. Caesarean section have become ever more common in both developed and developing countries. ${ }^{15,16}$ The reason for this can be varied. Medicolegal litigations in obstetric practice are increasing. ${ }^{17,18}$ In addition, majority of the study have concluded that oligohydramnios and polyhydramnios is associated with increased perinatal complications. ${ }^{6-9,11,13}$ All these factors have lead to a negative trend of increased caesarean section rates. Conducting a randomized control trial on the optimal delivery route for oligohydramnios or polyhydramnios conditions is the best solution, but has ethical issues. Long term complications of caesarean section should also be kept in mind to prevent unnecessary surgeries. ${ }^{15}$

\section{CONCLUSION}

In our study, both oligohydramnios and polyhydramnios were found to be associated with increased caesarean section rates, NICU admissions and neonatal mortality. Antenatal detection of abnormal liquor volume is imperative for proper counselling and management. Abnormal liquor volume warrants close monitoring of pregnant women during labour to prevent complications.

\section{ACKNOWLEDGMENTS}

Authors would like to thank Dr. Ashwini for her support and Dr. Raghavendra Bellara, Associate Professor, Department of Community Medicine, VIMS, Ballari, for guidance in statistical analysis.

\section{Funding: No funding sources}

Conflict of interest: None declared

Ethical approval: The study was approved by the Institutional Ethics Committee

\section{REFERENCES}

1. Brace RA, Cheung CY. Regulation of amniotic fluid volume: evolving concepts. Advances in Fetal and Neonatal Physiology. 2014:49-68.

2. Ackerman CM, Moore TR, Lipkind HS. Abnormal Amniotic Fluid Volume. Protocols for High-Risk Pregnancies: An Evidence-Based Approach. 2020;407-19.

3. Lim KI, Butt K, Naud K, Smithies M. Amniotic Fluid: Technical Update on Physiology and Measurement. J Obstet Gynaecol Can. 2017;39(1):52-8.

4. Rabie N, Magann E, Steelman S, Ounpraseuth S. Oligohydramnios in complicated and uncomplicated pregnancy: a systematic review and meta-analysis. Ultrasound Obstet Gynecol. 2017;49(4):442-9.
5. Matěcha J, Nováčková M. Idiopathic polyhydramnios. Ceska Gynekol. 2020;85(6):417-21.

6. Smith G, Moraitis AA, Wastlund D, Thornton JG, Papageorghiou A, Sanders J, et al. A systematic review and cost-effectiveness analysis of the case for screening nulliparous women in late pregnancy using ultrasound. Health Technology Assessment. 2020.

7. Panda S, Jayalakshmi M, Shashi Kumari G, Mahalakshmi G, Srujan Y, Anusha V. Oligoamnios and Perinatal Outcome. J Obstet Gynecol India. 2017;67(2):104-8.

8. Thobbi VA, Sabahath S. A study of perinatal outcome in patients with low Amniotic Fluid Index (AFI). Age. 2017;20(40):60.

9. Geetha SK, Saraswathi K, Puri MS. Correlation of Amniotic Fluid Index (AFI) with Maternal and Perinatal Outcome in Antenatal Patients at Term Gestation. Ann Romanian Soc Cell Biol. 2021;358798.

10. Mathuriya G, Verma M, Rajpoot S. Comparative study of maternal and fetal outcome between low and normal amniotic fluid index at term. Int $\mathbf{J}$ Reprod Contracept Obstet Gynecol. 2017;6(2):640-4.

11. Chaudhary R, Dhama V, Singh S, Singh M. Correlation of reduced amniotic fluid index with neonatal outcome. Int J Reprod Contracept Obstet Gynecol. 2017;6(6):2401-6.

12. Ravi S, Allirathinam A, Priya S, Priya P, Radhakrishnan S. Normal and abnormal liquor volume and its correlation with perinatal outcome. New Indian J OBGYN. 2019;5(2):113-9.

13. Tajinder K, Ruchika S. Feto-Maternal Outcome in Pregnancies with Abnorma 1 AFI. IOSR J Dent Med Sci. 2016;15(4):71-5.

14. Bhagat M, Chawla I. Correlation of amniotic fluid index with perinatal outcome. J Obstet Gynecol India. 2014;64(1):32-5.

15. Sandall J, Tribe RM, Avery L, Mola G, Visser GH, Homer CS, et al. Short-term and long-term effects of caesarean section on the health of women and children. The Lancet. 2018;392(10155):1349-57.

16. Mascarello KC, Horta BL, Silveira MF. Maternal complications and cesarean section without indication: systematic review and meta-analysis. Rev Saúde Pública. 2017;51:105.

17. Tuffnell D. Medicolegal issues in obstetrics. Obstet Gynaecol Reprod Med. 2019;29(1):12-4.

18. Cegolon L, Mastrangelo G, Maso G, Dal Pozzo G, Ronfani L, Cegolon A, Heymann WC, Barbone F. Understanding factors leading to primary cesarean section and vaginal birth after cesarean delivery in the Friuli-Venezia Giulia Region (North-Eastern Italy), 2005-2015. Sci Rep. 2020;10(1):1-8.

19. Bastakoti R, Dangol A, Pradhan N. Amniotic Fluid Index and Perinatal outcome in term pregnancy in Dhulikhel hospital. J KIST Med Coll. 2021;3(1):2732.

Cite this article as: Vidyasagara $\mathrm{M}$, Chandrashekhar T, Raikar SS. Correlation of amniotic fluid index with fetomaternal outcome. Int J Reprod Contracept Obstet Gynecol 2021;10:3137-41. 